\title{
A pilot behavioural and biological surveillance survey for HIV and other bloodborne infections among Aboriginal people in Regina, Saskatchewan
}

\author{
Tarasuk $\mathbf{J}^{1 *}$, Ogunnaike-Cooke $\mathbf{S}^{1}$, Archibald $\mathrm{C}^{1}$, Poitras $\mathbf{M}^{2}$, Hennink $\mathbf{M}^{3}$, Lloyd $\mathrm{K}^{3}$, Faye $\mathbf{R}^{3}$, Abbas $\mathbf{Z}^{3}$, \\ Bourassa $C^{4}$, Masching $R^{5}$, Bennett $R^{1}$, MacLean $R^{1}$, Malloch $L^{1}, K^{3 i m ~ J^{1}}$ \\ ${ }^{1}$ Centre for Communicable Diseases and Infection Control, Public Health Agency of Canada, Ottawa, ON \\ ${ }^{2}$ All Nations Hope Network, Regina, SK \\ ${ }^{3}$ Regina Qu'Appelle Health Region, Regina, SK \\ ${ }^{4}$ First Nations University of Canada, Regina, SK \\ ${ }^{5}$ Canadian Aboriginal AIDS Network, Dartmouth, NS \\ * Correspondence: jill.tarasuk@phac-aspc.gc.ca
}

\section{Abstract}

Background: Aboriginal people in Canada are disproportionately affected by HIV and other blood-borne infections. A-Track is a national public health surveillance system designed to monitor HIV and related infections, behaviours and socio-demographic factors among Aboriginal populations in Canada. The pilot survey for the ATrack surveillance system, the first of its kind in Canada, was conducted in Regina, Saskatchewan and implemented via a community and public health partnership.

Objective: To assess the prevalence of HIV, hepatitis C, syphilis and associated risk behaviours and sociodemographic factors among Aboriginal people in Regina, Saskatchewan. This focus of the pilot survey was to provide this surveillance information for public health action and to determine whether this type of public health surveillance activity could be conducted in an urban setting across Canada.

Methods: Survey participants were self-identified Aboriginal people (First Nations, Inuit or Métis) or those who claimed Aboriginal ancestry and between the ages of 16 and 60 years. These individuals were also asked to provide a blood sample for HIV, hepatitis $\mathrm{C}$ and syphilis antibody testing. Descriptive analyses were performed with sex-based comparisons.

Results: There were 1064 people who participated in the survey. Their average age was 33 years and $51 \%$ were male. The majority of participants (93\%) lived in urban Regina at the time of the survey. Just over half $(53.2 \%)$ of all participants had been removed from their families during childhood; $29.9 \%$ had lived in a residential or boarding school during childhood; and $57.7 \%$ had lived at some point in a correctional facility. Among the 1,045 participants who provided a blood sample of sufficient quantity for testing, $5.2 \%$ were HIV seropositive and $55.8 \%$ of these were aware of their HIV status. The lifetime exposure to hepatitis C was $41.6 \%$, with significantly higher proportions of males than females testing positive for hepatitis $C$ exposure. Syphilis seroprevalence was very low $(<1 \%)$. Almost three-quarters $(71.5 \%)$ of participants reported being tested for HIV at least once in their lifetime and among those ever tested, $67.6 \%$ had been tested during the 12 months prior to the interview.

Conclusion: Aboriginal people are disproportionately affected by the HIVIAIDS epidemic in Canada. The findings from the A-Track pilot survey can be used to inform and evaluate prevention and treatment services for HIV and other related infections among Aboriginal people. Lessons learned from the pilot survey could also be used to guide the possible implementation of A-Track in other urban and/or reserve locations in Canada. 


\section{Introduction}

In Canada, Aboriginal people remain disproportionately affected by HIVIAIDS. It is estimated that in 2011, Aboriginal people made up $12.2 \%$ of new HIV infections (1). At the end of $2011,8.9 \%$ of those living with HIV in Canada were Aboriginal people (1). By comparison, Aboriginal people represented $4.3 \%$ of the Canadian population in the 2011 census (2).

A-Track is a behavioural and biological surveillance system developed to monitor the prevalence of HIV and other related infections as well as associated risk behaviours and socio-demographics among Aboriginal populations in Canada. The A-Track system was piloted in Regina, Saskatchewan from 2011 to 2012. The focus of the pilot survey was to provide important surveillance information and determine whether this type of public health surveillance activity could be conducted in urban settings in Canada.

This report provides selected findings from the A-Track pilot survey and is a summary of a more in-depth report entitled Summary of key finding from the A-Track pilot survey, 2011 - 2012 (3).

\section{Methods}

A-Track is a behavioural and biological surveillance system that monitors the prevalence of HIV and other related infections as well as the associated risk behaviours and socio-demographics among Aboriginal populations in Canada. A pilot survey was launched in Regina, Saskatchewan, from December 5, 2011 to June 15, 2012.

The A-Track pilot survey was developed and implemented via a community and public health partnership. The partners included: a Community Advisory Group, All Nations Hope Network, Regina Qu'Appelle Health Region, the Canadian Aboriginal AIDS Network, First Nations University of Canada and the Public Health Agency of Canada.

The A-Track surveillance system recognizes Aboriginal peoples' shared control over data, respects Aboriginal customs and is based on the tenants of mutual respect between all stakeholders, the recognition of shared responsibility, Aboriginal community involvement and the utilization of existing local expertise. The surveillance system protocol recognizes First Nations, Inuit and Métis communities-specific culturally competent ethical research practices including the principles of data ownership, control, access and possession and protection (4) and follows the Tri-Council Policy Statement: Ethical Conduct for Research Involving Humans (5) and the Canadian Institutes of Health Research Guidelines for Health Research Involving Aboriginal People (6). The data from the Regina pilot survey is managed collaboratively by the All Nations Hope Network, the Regina Qu'Appelle Health Region and the Public Health Agency of Canada.

The target population for the pilot survey was people who self-identified as Aboriginal (First Nations, Inuit or Métis) or claimed Aboriginal ancestry and were between the ages of 16 and 60 years. Participation was voluntary, completely anonymous and based on informed verbal consent. Participants were recruited from community-based organizations, Friendship Centres, healthcare service points and other relevant venues in Regina.

Consenting participants were asked to complete a questionnaire covering demographics, sexual behaviour, drug use, HIV and hepatitis C testing / treatment history, access to health services and HIV-related knowledge. Participants were also asked to provide a finger prick blood sample which was tested for HIV, hepatitis $\mathrm{C}$ and syphilis antibodies.

The data in this report are descriptive results shown for the overall sample (as well as by sex) allowing for comparisons between male and female participants for demographics, antibody laboratory results, sexual and drug use behaviours and HIV testing, care and treatment. Findings for self-reported HIV, sexually transmitted infection and tuberculosis infection status, access to health services and HIV-related knowledge are not presented here and can be obtained from the full report (3). Where data in the table contain small cell counts, results should be interpreted with caution. 


\section{Results}

A total of 1,064 individuals participated in the A-Track pilot survey, two of whom claimed Aboriginal ancestry and 1,062 of whom self-identified as Aboriginal. (Table 1) Of these 1,062, the majority (90.1\%) self-identified as First Nations. Just over half $(50.7 \%)$ of the participants were male and just under half $(44.8 \%)$ of the participants were between the ages of 30 and 49 years, with a slightly lower proportion $(42.2 \%)$ under the age of 29 years and over the age of $50(13.0 \%)$. While the majority of participants $(95.5 \%)$ self-reported their sexual orientation as heterosexual or straight, a significantly higher proportion of females than males self-identified as gay, lesbian, bisexual or other $(6.9 \%$ versus $2.2 \%)$.

Table 1: Demographic characteristics of A-Track pilot survey participants

\begin{tabular}{|c|c|c|c|c|}
\hline $\begin{array}{c}\text { Demographic characteristic and past } \\
\text { experiences }\end{array}$ & $\begin{array}{c}\text { Total } \\
(n=1064)\end{array}$ & $\begin{array}{c}\text { Male } \\
(n=539)\end{array}$ & $\begin{array}{l}\text { Female } \\
(n=525)\end{array}$ & p-value \\
\hline $\begin{array}{l}\text { Aboriginal subgroup }(\mathrm{n}=1062) \\
\text { First Nat }\end{array}$ & $\begin{array}{l}90.1 \%(957) \\
9.7 \%(103) \\
<1 \%\end{array}$ & $\begin{array}{c}88.8 \%(477) \\
11.0 \%(59) \\
<1 \%\end{array}$ & $\begin{array}{c}91.4 \%(480) \\
8.4 \%(44) \\
<1 \%\end{array}$ & 0.357 \\
\hline $\begin{array}{r}29 \text { and less } \\
30 \text { to } 49 \\
50 \text { and over }\end{array}$ & $\begin{array}{l}42.2 \%(449) \\
44.8 \%(477) \\
13.0 \%(138)\end{array}$ & $\begin{array}{l}37.5 \%(202) \\
48.2 \%(260) \\
14.3 \%(77)\end{array}$ & $\begin{array}{c}47.1 \%(247) \\
41.3 \%(217) \\
11.6 \%(61)\end{array}$ & 0.007 \\
\hline $\begin{array}{r}\text { Sexual orientation ( } \mathrm{n}=1064) \\
\text { Gay, lesbian, bisexual and other } \\
\text { Heterosexual or straight }\end{array}$ & $\begin{array}{c}4.5 \%(48) \\
95.5 \%(1016)\end{array}$ & $\begin{array}{c}2.2 \%(12) \\
97.8 \%(527)\end{array}$ & $\begin{array}{c}6.9 \%(36) \\
93.1 \%(489)\end{array}$ & $<0.001$ \\
\hline $\begin{array}{l}\text { Highest completed level of education } \\
(\mathrm{n}=1064) \\
\text { Completed some high school or less } \\
\text { Completed high school } \\
\text { Completed more than high school }\end{array}$ & $\begin{array}{l}60.2 \%(640) \\
19.5 \%(208) \\
20.2 \%(214)\end{array}$ & $\begin{array}{l}60.3 \%(325) \\
20.2 \%(109) \\
19.3 \%(104)\end{array}$ & $\begin{array}{l}60.0 \%(315) \\
18.9 \%(99) \\
21.0 \%(110)\end{array}$ & 0.733 \\
\hline $\begin{array}{l}\text { Total household income }(\mathrm{n}=738)^{1} \\
\text { Up to } \$ 9,999 \\
\$ 10,000 \text { to } \$ 39,999 \\
\$ 40,000 \text { or more }\end{array}$ & $\begin{array}{l}27.1 \%(200) \\
51.1 \%(377) \\
21.8 \%(161)\end{array}$ & $\begin{array}{c}27.7 \%(100) \\
46.3 \%(167) \\
26.0 \%(94)\end{array}$ & $\begin{array}{c}26.5 \%(100) \\
55.7 \%(210) \\
17.8 \%(67)\end{array}$ & 0.011 \\
\hline $\begin{array}{l}\text { Proportion who were ever removed or } \\
\text { separated from family during childhood by } \\
\text { child welfare agencies, church or government } \\
\text { officials ( } n=1063 \text { ) }\end{array}$ & $53.2 \%(565)$ & $53.0 \%(285)$ & $53.3 \%(280)$ & 0.907 \\
\hline $\begin{array}{l}\text { Proportion who ever attended residential or } \\
\text { boarding school for Aboriginal children } \\
\text { during childhood ( } n=1061)\end{array}$ & $29.9 \%$ (317) & $32.1 \%(172)$ & $27.6 \%(145)$ & 0.112 \\
\hline $\begin{array}{l}\text { Proportion who were ever placed in a foster } \\
\text { home or in foster care during childhood } \\
(n=1060)\end{array}$ & $43.4 \%(460)$ & $41.7 \%(223)$ & $45.1 \%(237)$ & 0.256 \\
\hline
\end{tabular}




\begin{tabular}{|c|c|c|c|c|}
\hline $\begin{array}{l}\text { Housing status during the } 12 \text { months prior to } \\
\text { interview }(n=1064)^{2} \\
\text { Stable housing } \\
\text { Unstable housing } \\
\text { Mix of stable and unstable housing }\end{array}$ & $\begin{array}{c}73.5 \%(782) \\
6.4 \%(68) \\
20.1 \%(214)\end{array}$ & $\begin{array}{c}68.8 \%(371) \\
8.2 \%(44) \\
23.0 \%(124)\end{array}$ & $\begin{array}{c}78.3 \%(411) \\
4.6 \%(24) \\
17.1 \%(90)\end{array}$ & 0.001 \\
\hline $\begin{array}{l}\text { Proportion who moved during the } 12 \text { months } \\
\text { prior to interview for any reason }(n=1064)\end{array}$ & $33.3 \%$ (354) & $33.2 \%$ (179) & $33.3 \%$ (175) & 0.966 \\
\hline $\begin{array}{l}\text { Proportion who had ever lived in a } \\
\text { correctional facility }(n=1061)\end{array}$ & $57.7 \%(612)$ & $70.2 \%$ (376) & $45.0 \%(236)$ & $<0.001$ \\
\hline $\begin{array}{l}\text { Proportion who had lived in a correctional } \\
\text { facility during the } 12 \text { months prior to } \\
\text { interview ( } n=1064)\end{array}$ & $5.2 \%(55)$ & $7.2 \%(39)$ & $3.1 \%(16)$ & 0.002 \\
\hline
\end{tabular}

Income was measured as the total household income, before taxes and other deductions, from all sources for the year ending December $31,2010$.

${ }^{2}$ Participants were asked to indicate all of the types of places where they had continuously or occasionally lived during the 12 months prior to interview. Responses were categorized as stable housing, unstable housing and mix of stable and unstable housing. Stable housing included: living in an apartment or house or a relative's apartment or house during the 12 months prior to interview. Unstable housing included: living in a friend's place, hotel or motel room, rooming or boarding house, shelter or hostel, transition or halfway house, drug treatment facility, correctional facility, public place (e.g., street, squats), psychiatric institution, hospital or any other responses that were considered unstable (e.g., vehicle, tent, anywhere outdoors) within the 12 months prior to interview.

Just over half (51.1\%) of all participants who provided responses when asked about household income reported that their total household income was between $\$ 10,000$ and $\$ 39,000$. Significant differences were noted between the self-reported household incomes of males and females. Over half $(60.2 \%)$ of the participants had less than a high school education, $19.5 \%$ had completed high school and $20.3 \%$ had some post-secondary education.

Just over half (53.2\%) of all participants had been removed from their families during childhood; almost one-third $(29.9 \%)$ had at some time during childhood lived in a residential or boarding school; and $43.4 \%$ had been placed in foster care at some time during childhood. No significant differences were noted between males and females.

While only $6.4 \%$ of all participants reported living exclusively in unstable housing during the 12 months prior to interview, $20.1 \%$ reported a mix of unstable and stable housing. A significantly higher proportion of male than female participants reported unstable housing as well as a mix of unstable and stable housing during the 12 months prior to interview. One-third of participants (33.3\%) reported that they had moved for some reason within the 12 months prior to interview; no significant differences were noted between males and females.

Over half of all participants $(57.7 \%)$ had, at some time in their lives, lived in a correctional facility; for male participants, this proportion was significantly higher as compared to female participants. The proportion of male participants who had lived in a correctional facility in the 12 months prior to interview was significantly higher than the proportion of female participants $(7.2 \%$ versus $3.1 \%)$.

Table 2: HIV, hepatitis C and syphilis testing results for A-Track pilot survey participants

\begin{tabular}{|c|c|c|c|c|}
\hline Laboratory results & Total & Male & Female & p-value \\
\hline \multicolumn{5}{|c|}{ HIV seroprevalence (among participants who provided a blood sample, $n=1045)^{1}$} \\
\hline HIV seropositive & $5.2 \%(54)$ & $6.0 \%(32)$ & $4.3 \%(22)$ & 0.213 \\
\hline $\begin{array}{r}\text { Proportion of HIV seropositive } \\
\text { participants who reported a history } \\
\text { of injection drug use }(n=54)\end{array}$ & $92.6 \%(50)$ & $90.6 \%(29)$ & $95.5 \%(21)$ & $0.506^{5}$ \\
\hline $\begin{array}{r}\text { Proportion of HIV seropositive } \\
\text { participants who were aware of their } \\
\text { HIV positive status }(n=52)^{2}\end{array}$ & $55.8 \%(29)$ & $50.0 \%(15)$ & $63.6 \%(14)$ & 0.328 \\
\hline
\end{tabular}




\begin{tabular}{|c|c|c|c|c|}
\hline Hepatitis C seropositive & $41.6 \%(434)$ & $46.1 \%(245)$ & $36.9 \%(189)$ & 0.003 \\
\hline \multicolumn{5}{|c|}{$\begin{array}{l}\text { HIV and hepatitis C serostatus (among participants who provided a blood sample of sufficient quantity for } \\
\text { testing of both HIV and hepatitis C antibodies, } n=1044 \text { ) }\end{array}$} \\
\hline Seropositive for HIV only & $0.0 \%(0)$ & $0.0 \%(0)$ & $0.0 \%(0)$ & \multirow{4}{*}{0.011} \\
\hline Seropositive for hepatitis C only & $36.5 \%(381)$ & $40.2 \%(214)$ & $32.6 \%(167)$ & \\
\hline Seropositive for both HIV and hepatitis C & $5.1 \%(53)$ & $5.8 \%(31)$ & $4.3 \%(22)$ & \\
\hline Seronegative for both HIV and hepatitis C & $58.4 \%(610)$ & $54.0 \%(287)$ & $63.1 \%(323)$ & \\
\hline \multicolumn{5}{|c|}{ Lifetime exposure to syphilis (among participants who provided a blood sample, $n=1045)^{4}$} \\
\hline Syphilis seropositive & $0.2 \%(2)$ & $0.2 \%(1)$ & $0.2 \%(1)$ & $0.977^{5}$ \\
\hline
\end{tabular}

${ }^{1}$ HIV testing of dried blood spot (DBS) specimens was performed using the AVIOQ HIV-1 EIA assay. Confirmatory testing was subsequently performed using the Bio-Rad GS HIV-1 Western Blot assay. A positive result indicated a current HIV infection.

${ }^{2}$ Participants who reported that their last HIV test result was positive and who were found to be HIV seropositive based on testing of the biological specimen provided at the time of interview were classified as being aware of their HIV positive status.

${ }^{3}$ Hepatitis C testing of DBS specimens was performed using the Ortho HCV version 3.0 EIA. Confirmatory testing was not performed for samples that tested positive. A positive result indicated past or present hepatitis $\mathrm{C}$ infection and did not discriminate acute from chronic or resolved infections.

${ }^{4}$ Syphilis testing was performed using the Serodia ${ }^{\circledR}$ Treponema pallidum particle agglutination assay (TP-PA). Confirmatory testing was not performed for samples that tested positive. A positive result was due either to false positivity or the presence of antibodies against syphilis, which indicated either past or present syphilis infection but did not distinguish acute from chronic or resolved infections.

${ }_{5}^{5}$ Please note that due to small cell counts, Chi-squared results should be interpreted with caution.

Among the 1,045 participants who provided a blood sample of sufficient quantity for HIV testing, 54 participants (5.2\%) were found to be HIV positive and no significant differences were found between males and females (Table 2). Of the 54 participants who tested positive for HIV, the majority of both males and females had a history of injection drug use; overall, $92.6 \%$ of all HIV seropositive participants reported that they had, at some time in their lives, used injection drugs. Just over half $(55.8 \%)$ of the participants who were found to be HIV seropositive were aware of their HIV positive status and no significant differences were noted between males and females.

It is interesting to note that unawareness of HIV infection status was highest among participants who were HIV positive and who did not have a history of injection drug use. Among the 54 participants who tested positive for HIV, four had never injected and all of these participants $(4 / 4 ; 100 \%)$ were unaware of their HIV positive status (data not shown). By contrast, among the 50 participants who tested positive for HIV and had a history of injection drug use, $42 \%$ (21/50) were unaware of their HIV positive status (data not shown).

Among the 1,044 participants who provided a sample of sufficient quantity for hepatitis $C$ antibody testing, $41.6 \%$ were seropositive, with significantly higher proportions of males than females testing positive for hepatitis $\mathrm{C}$ exposure. A positive hepatitis $C$ result indicates past or present hepatitis $C$ infection and does not discriminate acute from chronic or resolved infections. Syphilis seroprevalence was very low among both males and females; overall, only $0.2 \%$ of participants were seropositive for syphilis. A positive syphilis result indicates past or present syphilis infection.

Although it is not possible to determine the proportion of participants that were co-infected with HIV and hepatitis $\mathrm{C}$ at the time of the survey due to the laboratory test used (i.e., it was not possible to distinguish present from past hepatitis $\mathrm{C}$ infection), $5.1 \%$ of participants were found to be seropositive for both HIV and hepatitis C. A significantly higher proportion of males than females tested positive for both HIV and hepatitis $\mathrm{C}$ antibodies.

Table 3: Injecting behaviours of the A-Track pilot survey participants

\begin{tabular}{|l|c|c|c|c|}
\hline \multicolumn{1}{|c|}{ Injecting behaviour } & Total & Male & Female & p-value \\
\hline Proportion who had ever injected drugs (n=1063) & $50.0 \%(532)$ & $53.4 \%(287)$ & $46.7 \%(245)$ & 0.029 \\
\hline $\begin{array}{l}\text { Proportion that were identified as HIV seropositive } \\
\text { based on testing of biological sample among those } \\
\text { who reported ever injecting drugs (n=528) }\end{array}$ & $9.5 \%(50)$ & $10.2 \%(29)$ & $8.6 \%(21)$ & 0.549 \\
\hline
\end{tabular}




\begin{tabular}{|c|c|c|c|c|}
\hline $\begin{array}{l}\text { Proportion who first injected before the age of } 16 \\
\text { ( } n=531)\end{array}$ & $19.4 \%(103)$ & $19.5 \%(56)$ & $19.3 \%(47)$ & 0.942 \\
\hline $\begin{array}{l}\text { Proportion who had injected drugs in the six } \\
\text { months prior to interview }(n=1064)\end{array}$ & $30.3 \%(322)$ & $32.5 \%(175)$ & $28.0 \%(147)$ & 0.113 \\
\hline \multicolumn{5}{|c|}{$\begin{array}{l}\text { Injecting behaviours among participants who reported injecting drugs in the six months prior to interview } \\
(n=322)\end{array}$} \\
\hline $\begin{array}{l}\text { Proportion who used sterile needles and/or } \\
\text { syringes at last injection }(n=321)^{1}\end{array}$ & $98.8 \%(317)$ & $97.7 \%(170)$ & $100 \%(147)$ & 0.064 \\
\hline $\begin{array}{l}\text { Proportion who injected with a used needle and/or } \\
\text { syringe in the six months prior to interview }(n=319)\end{array}$ & $9.1 \%(29)$ & $8.7 \%(15)$ & $9.6 \%(14)$ & 0.776 \\
\hline \multicolumn{5}{|l|}{$\begin{array}{l}\text { Most commonly reported injection drugs used in } \\
\text { the six months prior to interview }\end{array}$} \\
\hline Cocaine & $56.7 \%(181)$ & $59.5 \%(103)$ & $53.4 \%(78)$ & 0.272 \\
\hline Non-prescribed morphine & $51.1 \%(163)$ & $54.9 \%(95)$ & $46.6 \%(68)$ & 0.138 \\
\hline Ritalin & $49.8 \%(159)$ & $49.1 \%(89)$ & $50.7 \%(74)$ & 0.782 \\
\hline Non-prescribed Talwin and Ritalin & $17.2 \%(55)$ & $16.2 \%(28)$ & $18.5 \%(27)$ & 0.587 \\
\hline Dilaudid (hydromorphone) & $15.7 \%(50)$ & $15.6 \%(27)$ & $15.8 \%(23)$ & 0.971 \\
\hline \multicolumn{5}{|l|}{$\begin{array}{l}\text { Most commonly reported person with whom } \\
\text { participants injected in the six months prior to } \\
\text { interview }{ }^{2}\end{array}$} \\
\hline Friend(s) or people you know well & $53.3 \%(171)$ & $55.2 \%(96)$ & $51.0 \%(75)$ & 0.458 \\
\hline Regular sex partner(s) & $47.7 \%(153)$ & $47.7 \%(83)$ & $47.6 \%(70)$ & 0.988 \\
\hline No one: you injected by yourself & $40.2 \%(129)$ & $42.0 \%(73)$ & $38.1 \%(56)$ & 0.482 \\
\hline \multicolumn{5}{|l|}{$\begin{array}{l}\text { Most commonly reported location of injection in } \\
\text { the six months prior to interview }\end{array}$} \\
\hline Your own apartment or house & $72.6 \%(233)$ & $77.0 \%(134)$ & $67.4 \%(99)$ & 0.053 \\
\hline Friend's place & $44.2 \%(142)$ & $46.6 \%(81)$ & $41.5 \%(61)$ & 0.364 \\
\hline Other family member's house or place & $20.9 \%(67)$ & $20.7 \%(36)$ & $21.1 \%(31)$ & 0.930 \\
\hline
\end{tabular}

${ }^{1}$ Based on international reporting requirements through the Global AIDS Response Progress Report (GARPR), though the GARPR indicator is based on respondents who report injecting drugs in the last month rather than the last six months.

${ }^{2}$ Participants were provided with a list of responses and were asked to check all those that applied to them. As participants could select more than one response, the total denominator is not shown.

Half of all participants $(50.0 \%)$ reported that they had, at some time in their lives, used injection drugs, with a significantly higher proportion of male participants reporting a history of injection drug use (Table 3). Among participants that reported having injected drugs at some time, $9.5 \%$ were found to be HIV seropositive based on testing of biological samples at the time of interview. Just under one-fifth $(19.4 \%)$ of participants who had ever injected drugs reported that they had first done so before the age of 16; no significant differences were found between male and female participants. Overall, almost one-third of all participants (30.3\%) had used injection drugs during the six months prior to interview, with no significant differences observed between males and females.

Of the 322 individuals who reported injection drug use in the six months prior to interview, the majority (98.8\%) had used a clean needle and/or syringe during their last injection, with similar proportions observed among male and female participants. However, almost one-tenth (9.1\%) had used a contaminated needle and/or syringe in the six months prior to interview and no significant differences were noted between males and females. With respect to the drugs or substances most commonly reported as being injected in the six months prior to interview, no significant differences were noted between males and females; cocaine, non-prescribed morphine and Ritalin were the three most commonly reported drugs used by both males and females. No significant differences were noted between males and females with respect to the people with whom they most often injected; among both males and females, friend(s) or people they knew well, followed by regular sex partner(s) were the most 
commonly reported persons with whom injection occurred. Among both males and females, their own apartment or house was the most commonly reported location of injection in the six months prior to interview.

Several of the sexual behaviour indicators listed in the table below are consistent with those required for international reporting, namely the Global AIDS Response Progress Report (GARPR). Refer to the footnotes for specification of which indicators are consistent with GARPR.

Table 4: Sexual behaviours of A-Track pilot survey participants

\begin{tabular}{|c|c|c|c|c|}
\hline Sexual behaviour & Total & Male & Female & p-value \\
\hline $\begin{array}{l}\text { Proportion who first had sexual intercourse before } \\
\text { the age of } 15 \text { (among participants } 16 \text { to } 24 \text { years old, } \\
n=266)^{1}\end{array}$ & $41.0 \%$ (109) & $50.0 \%(58)$ & $34.0 \%(51)$ & 0.009 \\
\hline $\begin{array}{l}\text { Proportion who had more than one sexual partner in } \\
\text { the } 12 \text { months prior to interview }(n=926)^{1,2}\end{array}$ & $42.7 \%$ (395) & $45.5 \%(210)$ & $39.9 \%(185)$ & 0.086 \\
\hline $\begin{array}{l}\text { Proportion who had used a condom at last sexual } \\
\text { intercourse (among participants aged } 16 \text { to } 49 \text { who } \\
\text { reported having had more than one sexual partner in } \\
\text { the } 12 \text { months prior to interview, } n=393)^{1}\end{array}$ & $52.7 \%(207)$ & $57.7 \%(120)$ & $47.0 \%(87)$ & 0.035 \\
\hline $\begin{array}{l}\text { Proportion who had a client sex partner in the } 12 \\
\text { months prior to interview, } n=876)^{3}\end{array}$ & $7.2 \%(63)$ & $3.1 \%(14)$ & $11.4 \%(49)$ & $<0.001$ \\
\hline $\begin{array}{l}\text { Proportion who used a condom at last sexual } \\
\text { intercourse with a client sex partner (among } \\
\text { participants who reported having had a client sex } \\
\text { partner in the } 12 \text { months prior to interview, } n=62 \text { ) }\end{array}$ & $82.3 \%(51)$ & $78.6 \%(11)$ & $83.3 \%(40)$ & $0.682^{4}$ \\
\hline
\end{tabular}

It was found that a significantly higher proportion of male than female participants between the ages of 16 and 24 years had their first sexual intercourse prior to the age of 15 years ( $50.0 \%$ of males versus $34.0 \%$ of females) (Table 4). Just under half (42.7\%) of all participants reported having had more than one sexual partner in the 12 months prior to interview, with similar proportions observed among males and females. Among those participants between the ages of 16 and 49 years who reported having more than one sexual partner in the 12 months prior to interview, a significantly higher proportion of male participants had used a condom at last sexual intercourse ( $57.7 \%$ of males versus $47.0 \%$ of females). Among those participants who reported having had a client sex partner in the 12 months prior to interview, $82.3 \%$ reported using a condom at last sexual intercourse and no significant differences were noted between males and females.

Table 5: HIV testing, care and treatment of A-Track pilot survey participants

\begin{tabular}{|l|c|c|c|c|}
\hline \multicolumn{1}{|c|}{ HIV testing, care and treatment } & Total & Male & Female & p-value \\
\hline Proportion who had ever tested for HIV (n=1049) & $71.5 \%(750)$ & $67.7 \%(360)$ & $75.4 \%(390)$ & 0.005 \\
\hline $\begin{array}{l}\text { Proportion who had tested for HIV in the 12 months } \\
\text { prior to interview (among participants who had ever } \\
\text { tested for HIV, } \mathbf{n = 7 5 0 )}\end{array}$ & $67.6 \%(507)$ & $68.9 \%(248)$ & $66.4 \%(259)$ & 0.469 \\
\hline $\begin{array}{l}\text { Proportion who reported that they were currently } \\
\text { under the care of a doctor for HIV (among } \\
\text { participants who self-reported being HIV positive, }\end{array}$ & $86.7 \%(26)$ & $80.0 \%(12)$ & $93.3 \%(14)$ & $0.283^{2}$ \\
\hline
\end{tabular}




\begin{tabular}{|l|l|l|l|l|}
\hline $\mathbf{n}=\mathbf{3 0})^{\mathbf{1}}$ & & & \\
\hline $\begin{array}{l}\text { Proportion who had ever taken prescribed drugs for } \\
\text { HIV (among participants who self-reported being HIV } \\
\text { positive, } \mathbf{n = 3 0}\end{array}$ & $66.7 \%(20)$ & $73.3 \%(11)$ & $60.0 \%(9)$ & 0.439 \\
\hline
\end{tabular}

${ }^{1}$ Defined as a single visit or more to a doctor or other health professional in the six months prior to interview for HIV testing, treatment, counselling, etc.

${ }^{2}$ Please note that due to small cell counts, Chi-squared results should be interpreted with caution.

Just under three-quarters (71.5\%) of participants reported that they had been tested for HIV at least once during their lifetime, and history of HIV testing was significantly higher among female than male participants (Table 5). Of the 750 individuals who had ever been tested for HIV, 67.6\% had been tested during the 12 months prior to the interview, with similar proportions among males and females. Among participants who reported being HIV positive, $86.7 \%$ reported that they were under the care of a doctor at the time of the interview and $66.7 \%$ reported that they had, at some time, taken prescription drugs for HIV. No significant differences were found between males and females.

\section{Conclusion}

Findings from the A-Track pilot survey are consistent with other findings that suggest Aboriginal populations in Canada are disproportionately affected by HIV (7-15). These findings also suggest that numerous risk behaviours may be contributing to the transmission of HIV and other blood-borne infections among Aboriginal populations and therefore underscore the continued need for health and social support services, as well as testing for HIV and other blood-borne infections. An analysis of the Aboriginal Social Determinants of Health would further inform service development and delivery by contextualizing the environments of risk and resilience that influence behaviours.

There are however limitations to the findings. The pilot survey only included Aboriginal people recruited at community and healthcare venues in Regina and thus, findings cannot be said to be representative of all Aboriginal people in Regina or of all Aboriginal people in Canada. In addition, the A-Track pilot survey findings are based on self-reported data and it is therefore possible that certain risk behaviours were over or underrepresented. These limitations notwithstanding, findings from the A-Track pilot survey - the first of its kind in Canada - provide valuable information for treatment and prevention services and programs at local, provincial and national levels. This surveillance data can be used to inform existing interventions and to design new strategies aimed at decreasing the risk of HIV and related infections among Aboriginal people in Canada.

In conclusion, this assessment of the pilot survey design and implementation processes and outputs has demonstrated the feasibility of such a behavioural and surveillance system for urban settings in Canada and provide lessons for use in future surveys of its kind.

\section{Acknowledgements}

The A-Track Pilot Survey in Regina was a partnership among All Nations Hope Network, Regina Qu'Appelle Health Region, the First Nations University of Canada, the Canadian Aboriginal AIDS Network and the Public Health Agency of Canada. We acknowledge and recognize the contributions of the A-Track survey participants, the survey field staff, the survey venues, the Community Advisory Committee members and the A-Track Pilot Survey Team (Margaret Poitras [principal investigator], Maurice Hennink [principal investigator], Kathy Lloyd, Rachel Faye, Zahid Abbas, Carrie Bourassa, Renée Masching, Jill Tarasuk, Susanna Ogunnaike-Cooke [principal investigator], Chris Archibald). We acknowledge the support from the National HIV \& Retrovirology Laboratories (Paul Sandstrom, John Kim, Laurie Malloch, Richard Pilon), the National Microbiology Laboratory (Raymond Tsang) and the members of the Public Health Agency of Canada A-Track Surveillance Team (Chris Archibald, Susanna Ogunnaike-Cooke, Jill Tarasuk, Rachel Bennett, Rachel MacLean, Stephen Cule). 


\section{Conflict of interest}

None

\section{Funding}

This work was supported by the Public Health Agency of Canada.

\section{References}

(1) Public Health Agency of Canada. Summary: Estimates of HIV prevalence and incidence in Canada, 2011. Ottawa: PHAC; 2012.

(2) Statistics Canada. Population and dwelling count highlight tables, 2011 Census. Ottawa: Statistics Canada; 2012. http://www12.statcan.gc.ca/census-recensement/2011/dp-pd/hlt-fst/pd-pl/index-eng.cfm

(3) Public Health Agency of Canada. Summary of key findings from the A-Track pilot survey, 2011-2012. Ottawa: PHAC; 2014 http://www.phac-aspc.gc.ca/aids-sida/publication/reports/a-track/index-eng.php

(4) First Nations Centre. OCAP: Ownership, control, access and possession. Sanctioned by the First Nations Information Governance Committee, Assembly of First Nations. Ottawa: National Aboriginal Health Organization; 2007.

(5) Tri-Council policy statement: Ethical conduct for research involving humans. Canadian Institutes of Health Research, Natural Sciences and Engineering Research Council of Canada, and Social Sciences and Humanities Research Council of Canada; December 2010.

(6) Canadian Institutes for Health Research. Guidelines for health research involving Aboriginal people. Ottawa: Canadian Institutes of Health Research; 2007.

(7) Sullivan A, Swantee C, Rank C, Liu J, et al. Race/ethnicity of newly diagnosed HIV cases in Ontario, 2009 to 2011.2011 Ontario HIV Treatment Network Research Conference. Toronto, Ontario. November 14, 2011 (Abstract 138). http://conference.ohtn.on.ca/past-conferences/2011/Presentations/138.php

(8) Becker ML, Kasper K, Pindera C, et al. Characterizing the HIV epidemic in the prairie provinces. Can J Infect Dis Med Microbiol. 2012; 23(1):19-22.

(9) Becker M, Kasper K, Pindera C, Cheang M, et al. Evolution of the HIV epidemic in the prairie provinces. Can J Infect Dis Med Microbiol. 2010; Summer; 21(Suppl B):21B (Abstract O043).

(10) Rank C, Bangura H, Gilbert M, et al. Distribution and correlates of recent HIV infection in four Canadian provinces, 20002008. Can J Infect Dis Med Microbiol. 2012; Spring;23(Suppl A): 86A (Abstract P148).

(11) Halverson J, Shea B, Andersson N, et al. Unequal burden: comparison of HIV diagnosis rates among Aboriginal and Caucasian populations in Canada. Can J Infect Dis Med Microbiol. 2011; Spring;22(Suppl B): 31B (Abstract O072).

(12) Khan I, Smith LA, Bukassa Kazadi G, et al. Know your status: outcomes of a community-based multi-disciplinary HIV testing and care project in a Saskatchewan First Nations community. Can J Infect Dis Med Microbiol. 2012; Spring;23(Suppl A):77A (Abstract P116).

(13) Oviedo-Joekes E, Christian WM, Pearce ME, Schechter MT, Spittal PM. The Cedar Project: vulnerabilities associated with HIV incidence among young Aboriginal people who use injection and non-injection drugs in two Canadian cities. Can $\mathrm{J}$ Infect Dis Med Microbiol. 2011; Spring;22(Suppl B):30B-31B (Abstract O070).

(14) Palmer A, Forrest JI, Wang H, et al. Cohort profile: longitudinal investigations into supportive and ancillary health services (LISA). Can J Infect Dis Med Microbiol. 2011; Spring;22(Suppl B):93B-94B (Abstract P186).

(15) Marshall C, Lalonde K, Halverson J, Archibald C. An older, changing face: HIVIAIDS trends among Canadians 50 years of age and older. Can J Infect Dis Med Microbiol. 2010; Summer;21(Suppl B):66B (Abstract P199). 